\title{
Negative Regulation of G0 to G1 Transition
}

National Cancer Institute

\section{Source}

National Cancer Institute. Negative Regulation of GO to G1 Transition. NCI Thesaurus. Code $C 40772$

G0 to G1 Phase Arrest consists of interference with, or restraint of, activities that regulate cellular capability to transition from the resting stage (between successive cell divisions) and the initial phase of the cell cycle (Gap 1 phase), preceding DNA synthesis. G1 subphases include competence, entry (G1a), progression (G1b), and assembly (G1c), based on effects of limiting growth factors, nutrients, or inhibitors. 